\title{
Analisis Karakter Segmen Abnormal pada Citra Mamografi dengan Menggunakan Berbagai Metode Preprocessing Citra
}

\author{
Ni Larasati Kartika Sari ${ }^{1 *}$, Maria Oktavianti ${ }^{2}$, Samsun $^{2}$ \\ ${ }^{1}$ Program Studi Fisika, Fakultas Teknik dan Sains, Universitas Nasional, Jakarta \\ ${ }^{2}$ Program Studi Teknik Radiodiagnostik, Politeknik Kesehatan Kementrian Kesehatan Jakarta II, \\ Jakarta \\ *Korespondensi penulis: nilarasati@civitas.unas.ac.id
}

\begin{abstract}
Abstrak. Penelitian ini menganalisis pengaruh penerapan beberapa jenis algoritma preprocessing untuk mencari karakteristik segmen abnormal yang tampak pada citra mamografi. Mamografi merupakan pemeriksaan radiografi khusus payudara. Penerapan algoritma preprocessing yang terdiri dari metode filtering, contrast enhancement, sharpening, dan smoothing diharapkan dapat mengurangi noise dan meningkatkan kontras citra mamografi serta membantu ahli radiologi untuk melakukan diagnosis pada citra. Pada penelitian ini akan digunakan dua algoritma filtering yaitu median filter dan gaussian filter. Selain itu digunakan dua algoritma contrast enhancement yaitu global histogram equalization dan CLAHE (Contrast Limited Adaptive Histogram Equalization). Nilai piksel rata-rata segmen abnormal berkisar antara 206.9-213.3 dan rasio sumbu minor/mayor segmen abnormal berkisar antara 0.5-0.7.Pemilihan jenis metode filter (median filter dan gaussian filter) tidak mempengaruhi hasil nilai piksel rata-rata maupun rasio sumbu minor/mayor dan ukuran segmen abnormal, namun pemilihan jenis metode peningkatan kontras (CLAHE dan global histogram equalization) menghasilkan segmen abnormal dengan ukuran yang berbeda. Metode global histogram equalization menghasilkan segmen abnormal yang tidak dapat dibedakan dengan sekitarnya sehingga hasil ekstrasi segmen terlalu besar.
\end{abstract}

Kata kunci: CLAHE, Filter Gaussian, global histogam equalization, filter median, nilai piksel.

\begin{abstract}
This study analyzes the effect of preprocessing algorithms' application to characterize abnormal segments shown in mammography images. Mammography is a dedicated radiological examination for breast. The application of image preprocessing algorithms that consist of filtering, contrast enhancement, sharpening, dan smoothing is expected to reduce noise and enhance the image's contrast therefore it can help radiologist to diagnose the image. Two filtering algorithms, median filter dan gaussian filter, and two contrast enhancement algorithms, global histogram equalization dan CLAHE (Contrast Limited Adaptive Histogram Equalization) were used in this study. Both of filtering and contrast enhancement algorithms gave the same result on the average pixel value and average ratio of minor/major axis. The average pixel value of abnormal segments were in the range of 206.9-213.3 and the average ratio of minor/major axis was in the range of 0.5-0.7. In the other hand, the size of abnormal segments detected is affected by the contrast enhancement algorithm selection. The global histogram equalization method results in bigger size segments that hard to differentiate from it's background.
\end{abstract}

Keywords: CLAHE, gaussian filter, global histogam equalization, median filter, pixel value.

\section{PENDAHULUAN}

Di Indonesia kanker payudara merupakan kanker yang paling banyak diderita oleh pasien kanker wanita. Berdasarkan Sistem Informasi Rumah Sakit (SIRS) pada tahun 2014 [1], jumlah pasien rawat jalan maupun rawat inap pada kanker payudara terbanyak yaitu 12.014 
orang $(28,7 \%)$ dan kanker serviks 5.349 orang $(12,8 \%)$. Terdapat berbagai modalitas untuk mendeteksi kanker payudara di Indonesia, salah satunya adalah mamografi. Pemeriksaan mamografi menggunakan sinar X karakterisktik dengan energi berkisar 17,5 hingga 22,7 $\mathrm{keV}$ sehingga dapat menghasilkan citra yang optimum dengan dosis yang wajar.

Kanker payudara adalah kanker yang terjadi karena terganggunya sistem pertumbuhan sel di dalam jaringan payudara. Payudara tersusun atas kelenjar susu, jaringan lemak, kantung penghasil susu, dan kelenjar getah bening [2]. Jaringan yang memiliki atenuasi hampir sama tersebut menyulitkan ahli radiologi untuk membaca hasil mamogram. Penelitian menunjukkan bahwa ahli radiologi dapat melewatkan bagian yang signifikan dari kelainan yang terdapat pada hasil mammogram. Diperkirakan sensitivitas ahli radiografi dalam deteksi kanker payudara hanya sekitar 75\% [3].

Untuk memudahkan proses diagnosis, telah dikembangkan teknik Computer Aided Diagnosis (CAD) [4, 5]. CAD merupakan sistem pengolahan citra digital dengan bantuan komputer. Pengolahan citra digital telah banyak dilakukan khususnya dibidang kedokteran sebagai alat bantu untuk mendiagnosis suatu penyakit termasuk untuk mendeteksi penyakit pada citra mammogram. Sistem CAD telah terbukti dapat berfungsi sebagai pembaca kedua yang terpercaya, akurat dan efisien [6]. Sensitivitas sistem CAD untuk deteksi mikrokalsifikasi maglinant adalah sebesar 99\%, sedangkan sensitivitas untuk mendeteksi massa maglinant dilaporkan sebesar 75-89\% [7]. Dasar sistem CAD terdiri dari preporcessing, segmentasi, ekstraksi fitur dan klasifikasi [8]. Penelitian ini mengevaluasi berbagai metode dalam tahap preprocessing yang terdiri dari filtering, contrast enhancement, smoothing dan egde sharpening. Terdapat berbagai algortima preprocessing. Perlu dilakukan analisis terhadap kemampuan tiap algoritma untuk membedakan karaktersitik objek abnormal yang tampak pada citra mamografi.

\section{METODE PENELITIAN}

\section{Alat dan Bahan Penelitian}

Penelitian ini menggunakan alat dan bahan seperti CD-RW sebanyak 10 buah untuk mengambil citra mamografi dari pesawat, citra mamografi, komputer/Laptop untuk mengolah citra, dan software Matlab 2017a. Adapun citra yang diambil merupakan citra yang memiliki ekspertise abnormal dari dokter radiologi, baik abnormalitas maglina maupun benign. Terdapat dua citra untuk tiap payudara, yaitu citra posisi Craunio Caudal (CC) dan Medio Lateral Oblique (MLO). Penenlitian ini dilakukan pada 25 citra mamografi tiap posisi, sehingga total terdapat 100 citra mamografi yang digunakan.

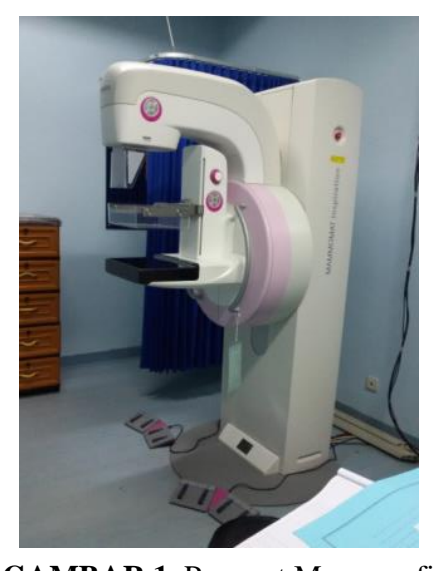

GAMBAR 1. Pesawat Mamografi

\section{Desain dan Langkah Kerja}

Penelitian ini, terdiri dari tahap pengambilan data abnormal beserta ekspertise dari dokter, selanjutnya dilakukan pengembangan program preprocessing citra dan ekstraksi segmen 
dengan variasi filter dan contrast enhancement, dan tahap evaluasi untuk menyimpulkan karakteristik seegmen abnormal. Adapun karakteristik segmen yang diamati adalah nilai piksel dan bentuk segmen. Evaluasi bentuk segmen dilakukan dengan melihat rasio sumbu minor/mayor. Segmen abnormal merupakan jaringan yang memiliki densitas yang lebih tinggi dibanding jaringan sekitarnya, maka jaringan tersebut akan tampak sebagai segmen yang lebih cerah atau memiliki nilai piksel yang lebih tinggi dibanding sekitarnya. Selain itu, jaringan abnormal memiliki bentuk yang berbeda dengan pembuluh darah atau saluran susu. Pembuluh darah dan saluran susu akan tampil sebagai segmen yang memanjang (memiliki rasio sumbu minor/mayor yang kecil). Sementara jaringan abnormal akan cenderung memiliki pertumbuhan abnormalitas ke segala arah, sehingga akan tampil sebagai segmen yang memiliki rasio sumbu minor/mayor mendekati satu.

Sementara itu, alur kerja dari program preprocessing dan pecarian karakteristik segmen dapat dilihat pada gambar 2. Sebelum melalui tahap preprocessing, citra terlebih dahulu dipersiapkan. Persiapan citra meliputi tahap pemotongan background dan konversi format citra. Citra digital mamografi yang didapat memiliki daerah background hitam yang lebih luas dibanding daerah interest payudara. Tahapan preprocessing (filter dan contrast enhancement) berdasarkan pada distribusi nilai piksel. Agar tidak mempengaruhi tahapan preprocessing, maka dilakukan pemotongan bagian background citra. Citra yang diambil dari rumah sakit memiliki format DICOM dan merupakan citra 16 bit. Citra dengan format tersebut masih terbatas proses pengolahannya pada software Matlab dan membutuhkan aplikasi khusus untuk membukanya yang tidak terdapat pada bawaan windows. Selain itu citra 16bit memiliki variasi nilai piksel yang terlalu besar, yaitu sekitar 60.000 variasi nilai piksel, sehingga menyulitkan dalam proses analisis segmen. Oleh karena itu, desain program yang dibuat memasukkan tahapan mengubah citra DICOM menjadi citra tiff 8bit untuk memudahkan dalam tahapan preprocessing selanjutya maupun evaluasi. Citra 8bit hanya memiliki 256 variasi nilai piksel, yaitu antara 0-255. Warna gelap (hitam) pada citra memiliki nilai piksel 0, sedangkan warna putih (paling cerah) memiliki nilai piksel 255.

TABEL 1. Variasi penggunaan filter dan contrast enhancement

\begin{tabular}{|c|c|c|c|c|}
\hline Kombinasi & Filter & Penajaman Citra & $\begin{array}{c}\text { Contrast } \\
\text { Enhancement }\end{array}$ & $\begin{array}{c}\text { Penghalusan } \\
\text { Citra }\end{array}$ \\
\hline Kombinasi 1 & \multirow[b]{2}{*}{ Median Filter } & \multirow[b]{2}{*}{ Unsharp Masking } & CLAHE & \multirow[b]{2}{*}{ Average Filter } \\
\hline Kombinasi 2 & & & $\begin{array}{l}\text { Global Histogram } \\
\text { Equalization }\end{array}$ & \\
\hline Kombinasi 3 & Gaussian Filter & Unsharp Masking & CLAHE & Average Filter \\
\hline Kombinasi 4 & & & $\begin{array}{l}\text { Global Histogram } \\
\text { Equalization }\end{array}$ & Average Filter \\
\hline
\end{tabular}

Program preprocessing dilanjutkan dengan tahap penapisan noise dengan menggunakan dua variasi filter yaitu, median filter dan gaussian filter. Tahapan ini bertujuan untuk mengurangi noise yang dapat mengganggu dalam proses karakterisasi segmen. Tahap berikutnya adalah peningkatan kontras dengan menggunakan dua variasi metode ekualiasi histogram, yaitu global histogram equalization dan CLAHE (Contrast Limited Adaptive Histogram Equalization). Langkah selanjutnya adalah menajamkan citra. Langkah ini bertujuan agar tepi/batasan objek tetap jelas serta dapat dibedakan satu dengan lainya. Tahap akhir adalah menghaluskan kembali citra dengan menggunakan average filter. Variasi filter dan contrast enhancement dapat dilihat pada tabel 1. Setelah melalui 4 tahap preprocessing selanjutnya citra akan dibagi ke dalam segmen-segmen dengan metode Otsu Thresholding, yaitu mengubah citra menjadi citra biner. Selanjutnya dilakukan pencarian karakteristik dari tiap segmen yang terdapat di citra. Karakteristik dari segmen abnormal sesuai dengan ekspertise dokter dicatat untuk dilakukan analisis lanjutan. Evaluasi hasil penelitian dilakukan dengan membandingkan nilai karakteristik segmen, yaitu nilai piksel dan rasio sumbu dari tiap metode. Data tersebut selanjutnya digunakan untuk menganalisis kinerja dari tiap metode dalam menampilkan segmen abnormal. Karakter bentuk segmen yang terdeteksi dicocokkan dengan ekspertise dokter. Selain itu, data tambahan berupa diameter segmen juga diamati untuk menilai secara kualitatif kinerja dari tiap metode. 


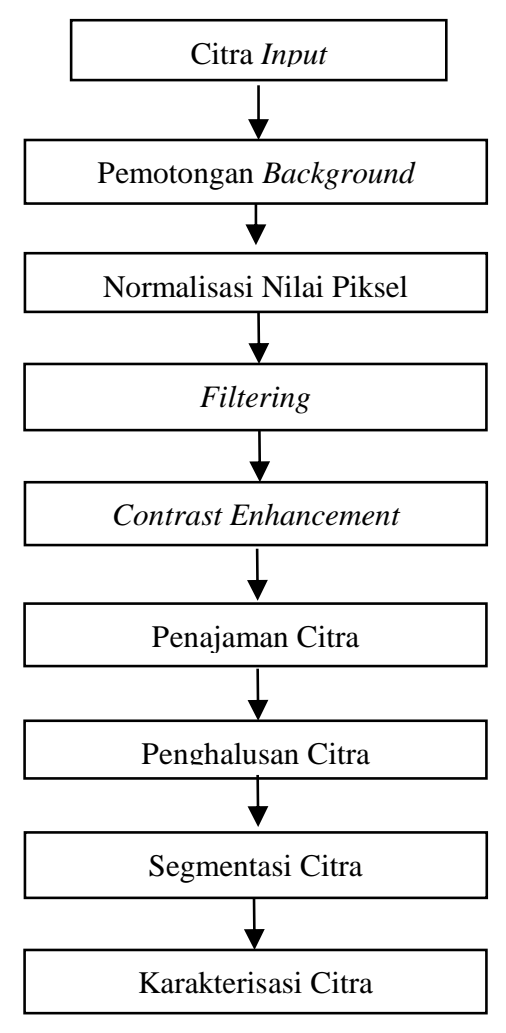

Gambar 2. Alur kerja program

\section{HASIL DAN PEMBAHASAN}

Proses karakterisasi segmen pertama kali dilakukan dengan mengubah citra menjadi citra biner (1 bit). Perubahan menjadi citra biner membuat segmen menjadi berwarna putih sementara background berwarna hiram. Selanjutnya dilakukan pemberian label pada segmen yang terdeteksi pada citra. Karakteristik tiap segmen seperti nilai piksel rata-rata, rasio sumbu minor/mayor, luas daerah, dan diameter juga dicari setelah proses pemberian label. Selanjutnya dilakukan ekstraksi segmen yang dicurigai abnormal dengan syarat nilai piksel $\geq 100$ dan rasio sumbu minor/mayor berada diantara $0,2-1,0$. Tahap terakhir adalah mencatat nilai piksel dan rasio sumbu pada segmen di daerah sesuai dengan ekspertise dari dokter radiologi. Tahapan proses perubahan ke citra biner, pemberian label, dan ekstraksi dapat dilihat pada gambar 3(a) hingga 3(c).



(a)



(b)

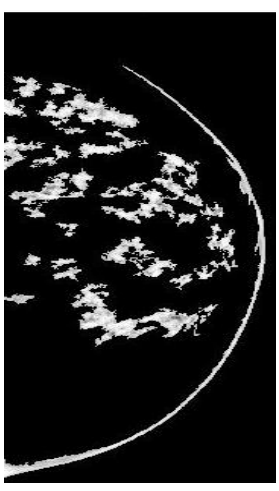

(c)

Gambar 3. (a) Citra biner (b) Citra setelah diberi label (c) Citra hasil ekstraksi

Pada Gambar 3(b) terlihat bahwa terdeteksi 31 segmen pada citra. Berdasarkan ekspertise dokter bahwa terdapat abnormalitas berbatas tegas pada kuadran superior (bagian atas dan 
luar), sehingga karakteristik segmen yang dicatat adalah segmen no. 21. Proses yang sama dilakukan pada semua citra dengan variasi metode filter dan contrast enhancement. Perbedaan metode ini menghasilkan bentuk dan nilai piksel segmen yang berbeda sehingga terdapat perbedaan dalam proses pemberian label. Hasil karakteristik segmen dari empat kombinasi metode untuk payudara kanan dapat dilihat pada Tabel 2, sementara untuk payudara kiri dapat dilihat pada Tabel 3.

TABEL 2. Karakteristik segmen abnormal payudara kanan.

\begin{tabular}{l|c|c|c|c|c|c|c|c}
\hline \multirow{2}{*}{ Karakteristik } & \multicolumn{2}{|c|}{ Kombinasi 1 } & \multicolumn{2}{c|}{ Kombinasi 2 } & \multicolumn{2}{c|}{ Kombinasi 3 } & \multicolumn{2}{c}{ Kombinasi 4 } \\
\cline { 2 - 9 } & CC & MLO & CC & MLO & CC & MLO & CC & MLO \\
\hline $\begin{array}{l}\text { Nilai piksel rata- } \\
\text { rata }\end{array}$ & 212,1 & 210,7 & 214,4 & 212,5 & 212,1 & 206,9 & 214,8 & 213,3 \\
\hline $\begin{array}{l}\text { Rasio sumbu } \\
\text { minor/mayor }\end{array}$ & 0,6 & 0,6 & 0,6 & 0,7 & 0,6 & 0,6 & 0,6 & 0,7 \\
\hline Diameter & 256,0 & 301,8 & 1139,8 & 1283,1 & 301,0 & 366,3 & 1178,3 & 1274,4 \\
\hline
\end{tabular}

TABEL 3. Karakteristik segmen abnormal payudara kiri.

\begin{tabular}{l|c|c|c|c|c|c|c|c}
\hline \multirow{2}{*}{ Karakteristik } & \multicolumn{2}{|c|}{ Kombinasi 1 } & \multicolumn{2}{c|}{ Kombinasi 2 } & \multicolumn{2}{c|}{ Kombinasi 3 } & \multicolumn{2}{c}{ Kombinasi 4 } \\
\cline { 2 - 9 } & CC & MLO & CC & MLO & CC & MLO & CC & MLO \\
\hline $\begin{array}{l}\text { Nilai piksel rata- } \\
\text { rata }\end{array}$ & 211,0 & 211,3 & 211,2 & 216,3 & 212,3 & 212,8 & 212,3 & 213,3 \\
\hline $\begin{array}{l}\text { Rasio sumbu } \\
\text { minor/mayor }\end{array}$ & 0,7 & 0,6 & 0,5 & 0,6 & 0,5 & 0,6 & 0,5 & 0,7 \\
\hline Diameter & 206,2 & 266,8 & 1237,4 & 1266,7 & 259,4 & 320,1 & 1198,7 & 1274,4 \\
\hline
\end{tabular}

Berdasarkan Tabel 2 dan 3, terlihat bahwa nilai piksel rata-rata segmen abnormal berkisar antara 206,9-213,3 dan rasio sumbu minor/mayor segmen abnormal berkisar antara 0,50,7 . Hal tersebut menunjukkan bahwa segmen abnormal memiliki karakteristik nilai piksel rata-rata yang tinggi (diatas 200), sehingga memiliki tampilan putih pada citra. Hal ini sesuai dengan kondisi bahwa abnormalitas pada payudra memiliki densitas yang lebih itnggi dibanding jaringan sekitarnya, sehingga memiliki atenuasi yang lebih besar terhadap Sinar-X, sehingga hanya sedikit berkas Sinar-X yang sampai ke detektor, sehingga menghasilkan objek berwarna putih pada citra. Selain itu, segmen abnormal memiliki rasio sumbu minor/mayor yang mendekati 1, yang menunjukkan bahwa abnormalitas pada payudara mengalami penyebaran ke segala arah, sehingga memiliki bentuk hampir lingkaran.

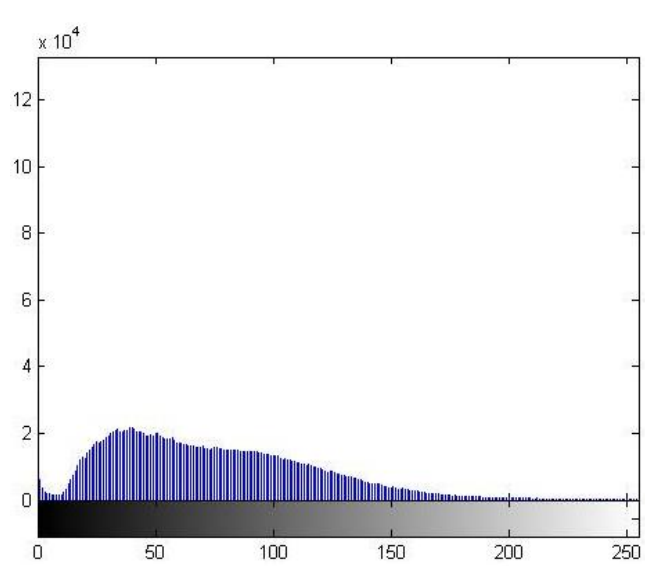

(a)

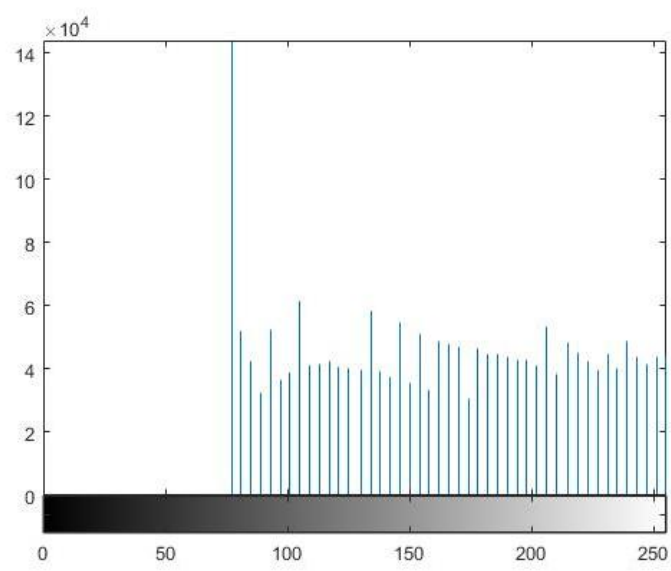

(b)

GAMBAR 4. (a) Histogram citra asli, (b) Histogram citra hasil ekualisasi histogram global.

Selain itu, pada Tabel 2 dan 3 juga terlihat bahwa diameter segmen abnormal pada kombinasi 2 dan kombinasi 4 jauh lebih besar dari kombinasi lainnya. Kedua kombinasi menggunakan contrast enhancement global histogram equalization. Berdasarkan hal 
tersebut, dapat dievaluasi bahwa kedua jenis metode peningkatan kontras memiliki cara kerja dan menghasilkan bentuk segmen yang berbeda. Global histogram equalization cenderung menggeser histogram ke arah tengah, seperti pada gambar 4, sehingga menghasilkan segmen yang lebih besar. Hal tersebut dapat meningkatkan visualisasi segmen abnormal, namun juga dapat menghasilkan segmen yang terlalu besar, sehingga sulit dibedakan antara satu segmen dengan lainya. Selain itu, jika digunakan pada citra normal kemungkinan dapat menghasilkan diagnosis false positive (citra normal terdeteksi abnormal). Perbedaan hasil kombinasi dapat dilihat pada gambar 5.



GAMBAR 5. Contoh 1 hasil citra dari 4 kombinasi 


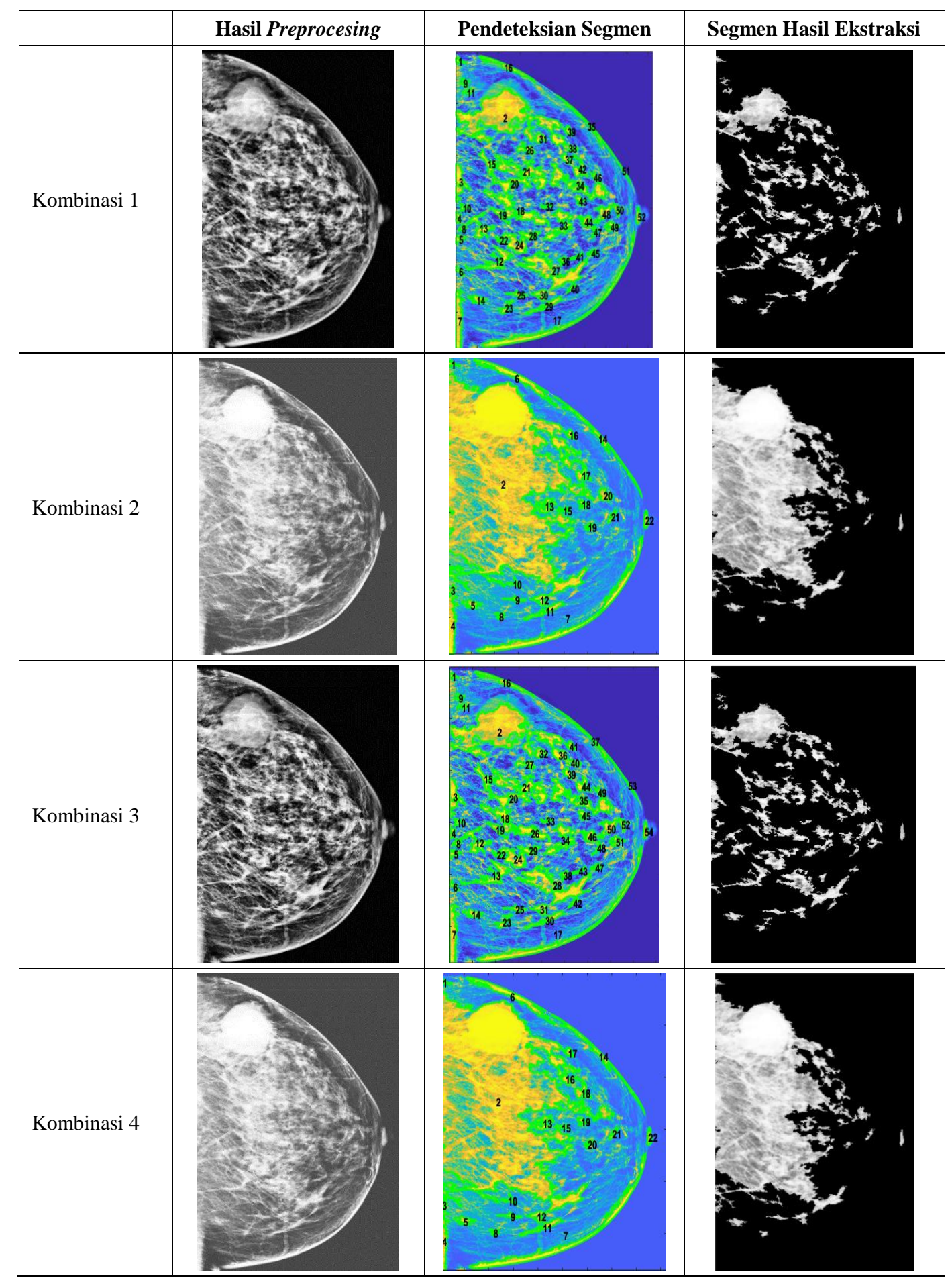

GAMBAR 6. Contoh 2 hasil citra dari 4 kombinasi

Ekspertise dari dokter untuk citra pada Gambar 5 adalah tampak multiple lesi berbatas cukup tegas pada kwadran superolateral dan medial kanan. Terlihat bahwa kombinasi 1 dan 3 mampu menghasilkan banyak segmen abnormal pada bagian superolateral dan median yang dapat dibedakan satu dengan lainnya. Sementara kombinasi 2 dan 4 menghasilkan sebuah segmen, yaitu segmen no. 2 yang sangat besar pada tengah payudara, sehingga tidak dapat menampilkan multiple lesi sesuai dengan ekspertise dokter. Citra hasil lainnya dapat dilihat pada Gambar 6. Citra tersebbut memiliki ekspertise tampak lesi berbatas tegas pada kwadran superolateral dan macrokalsifikasi superolateral dan inferomedial. Terlihat jelas pada citra terdapat sebuah lesi dengan ukuran cukup besar pada bagian kanan atas citra. Kombinasi 1 dan 3 menghasilkan segmentasi segmen yang spesifik 
(dapat dibedakan dengan segmen lain), namun ukuran segmen pada citra hasil ekstraksi (segmen no. 2) menjadi lebih kecil dibanding yang tampak pada citra hasil processing. Sementara itu, pada citra hasil processing kombinasi 2 dan 4, terlihat bahwa terdapat lesi dengan ukuran cukup besar pada bagian kanan atas citra yang memiliki batas yang tegas. Namun, saat dilakukan pendeteksian segmen dan ekstraksi, lesi tersebut tidak dapat dibedakan dengan daerah di sekitarnya, sehingga segmen yang dihasilkan terlalu besar, yaitu segmen no. 2 .

Berdasarkan Tabel 2 dan 3 serta Gambar 5 dan Gambar 5 menunjukkan bahwa variasi metode filter dan contrast enhancement tidak mempengaruhi nilai piksel rata-rata segmen abnormal, namun mempengaruhi bentuk dari segmen. Metode contrast enhancement CLAHE lebih unggul dibanding global histogram equalization. Jika dibandingkan dengan hasil penggunaan variasi contrast enhancement, penggunaan variasi filter, median filter dan gaussian filter, tidak terlalu mempengaruhi hasil karakterisasi segmen. Penggunaan metode segmentasi yang lebih kompleks Otsu Thresholding akan dapat membantu menghasilkan ekstraksi segmen yang lebih baik, sehingga mampu membantu dokter dalam melakukan diagnosis.

\section{KESIMPULAN}

Berdasarkan hasil penelitan, dapat diperoleh kesimpulan bahwa nilai piksel rata-rata segmen abnorm berkisar antara 206.9-213.3 dan rasio sumbu minor/mayor segmen abnormal berkisar antara 0.5-0.7. Selain itu, Pemilihan jenis metode filter (median filter dan gaussian filter) tidak mempengaruhi hasil nilai piksel rata-rata maupun rasio sumbu minor/mayor dan ukuran segmen abnormal, namun pemilihan jenis metode peningkatan kontras (CLAHE dan global histogram equalization) menghasilkan segmen abnormal dengan ukuran yang berbeda. Metode global histogram equalization menghasilkan segmen abnormal yang tidak dapat dibedakan dengan sekitarnya sehingga hasil ekstrasi segmen terlalu besar.

\section{DAFTAR PUSTAKA}

[1] Manafe, D. (2014). Di Indonesia, kasus kanker payudara dan serviks tertinggi. Diakses pada 15 Januari 2018. http://www.beritasatu.com/kesehatan/164592-diindonesia-kasus-kanker-payudara-dan-serviks-tertinggi.

[2] Sirait, M. R. (2011). Pengetahuan dan sikap suami tentang kanker payudara yang diderita. Universitas Negeri Sumatera Utara: repository.usu.ac.id.

[3] Bird, R.E. (1990). Professional quality assurance for mammography screening programs. Journal of Radiology, vol. 175, 587-605

[4] Nishikawa RM: Current status and future directions of computer aided diagnosis in mammography. Comput Med Imaging Graph 31(4):224-235, 2007

[5] Andreadis II, Spyrou GM, Nikita KS: A CAD scheme for mammography empowered with topological information from clustered microcalcifications atlases. IEEE J Biomed Health Inform 19(1): 166-173, 2015

[6] Laxman, S., Dubey, R.B., Jaffery, Z.A., dan Zaheeruddin, Z. (2009). Segmentation and characterization of brain tumor from MR images. 2009 International Conference on Advances in Recent Technologies in Communication and Computing, 815-819.

[7] Burhenne, L.W., Wood, S., dan D'Orsi C, et al. (2000). Potential contribution of computer-aided detection to the sensitivity of screening mammography. Radiology. 215:554-562.

[8] Jalalian, A., Mashohor, S., Mahmud, R., Karasfi, B., Saripan, M. I. B. , Ramli, A. R. B. (2017). Foundation and Methodologies in Computer-Aided Diagnosis Systems For Breast Cancer Detection. EXCLI Journal 2017;16:113-137 - ISSN 1611-2156 